\title{
Patient's Rights: Assessment of Knowledge and Practices of Physicians at Benha University Hospitals
}

\section{Abed-Rahim Shoulah}

Benha University Faculty of Medicine

Rabaa Abed Al-Hady

Benha University Faculty of Medicine

Rasha EL-Desouky

Benha University Faculty of Medicine

Eman Araby

Benha University Faculty of Medicine

Enjy E. Khedr ( $\nabla$ Enjy.khadr@fmed.bu.edu.eg )

Benha University Faculty of Medicine https://orcid.org/0000-0002-8582-2577

\section{Research}

Keywords: Patient's rights, Knowledge, Practice, Physicians

Posted Date: July 12th, 2021

DOI: https://doi.org/10.21203/rs.3.rs-665007/v1

License: (c) (i) This work is licensed under a Creative Commons Attribution 4.0 International License. Read Full License 


\section{Abstract}

Background: Patients' rights (PRs) mean a set of rights that an individual has in the healthcare organizations that ensure that they receive ethical treatment and high quality of care. PRs became an important topic in healthcare practices worldwide and essential for providing high quality care.

Aim: This study looked for assessment of knowledge and practices of physicians working in the authors' Benha University Hospitals, about PRs.

Method: A cross-sectional study was conducted using structured questionnaire included 20 questions concerning PRs. Study participants were 230 physicians \& 300 patients.

Results: $97.0 \%$ of the physicians achieved satisfactory score regarding knowledge about PRs ,but only $14.7 \%$ of them showed satisfactory score of practices (from patients' point of view). There is statistically significant difference between score of knowledge and practices of PRs $(p<0.001)$. The score of knowledge was affected by physicians' age, gender, highest qualification, work position, work experience and average number of working hours, while patients' opinion in physicians' practices of PRs was affected by patients' gender, educational level and department of admission. Patients' residence \& their length of hospital stay (LOS) did not significantly influenced their opinion.

Conclusion: There was discrepancy between knowledge and practices of PRs.

\section{Introduction}

PRs means the legal and ethical issues in the provider-patient relationship, including a person's right to privacy, the right to high quality medical care without prejudice, the right to make informed decisions about care and treatment options, and the right to refuse treatment,[1, 2]. It means receiving the right kind of medical care by the right healthcare providers at the right time using the right techniques without any discrimination of any kind,[3].

PRs became an important topic in healthcare practices worldwide,[4]. It is also considered an important item in healthcare Accreditation,[5]. Moreover, Awareness of patients about their rights will help improve quality of provided care, improve recovery, decrease duration of hospital stay, decrease physical and spiritual damage, decrease cost and increase dignity,[6].

Nowadays, healthcare systems in many countries have defined certain rights for patients, and the healthcare providers are obligated to abide by these rights when providing service. PRs vary in different countries often depending upon the prevailing cultural and social norms but there is growing international consensus that they include privacy, confidentiality of medical information, treatment refusal, proper information on healthcare services, consultation on medical emergencies, and acknowledgment of relevant risk of medical procedures, $[7,8]$. 
In Egypt, the patient's bill of rights was introduced into the Egyptian Hospital Accreditation standards, and was enforced in all hospitals across the country since 2005,[9, 10]. Also, the Egyptian Hospital Accreditation Standards has obligated each hospital to develop quality committee to monitor and evaluate practice of PRs among healthcare provider aiming at providing high quality of care; increasing the productivity, efficiency, effectiveness, and the satisfaction of the patient; and ensuring different dimensions of quality,[11].

\section{Objectives}

To assess knowledge of physicians about PRs using the Egyptian Hospital Accreditation Standards and to assess physicians' practice of these rights from patients' perspectives.

\section{Methodology}

This was a cross-sectional study conducted on both physicians who are working in general surgery, obstetrics and gynecology (O\&G), internal medicine and pediatrics departments and patients who were admitted in these departments. The field of work was carried out during the period from November 2018 to February 2019. Data were gathered using a questionnaire containing a set of questions filled out by physicians and patients themselves or his /her guardians or completed by the researcher on behalf of patients who can't read or write.

Sampling: Four clinical departments were chosen by simple random sampling method \& all physicians working in those departments were included. 230 physicians had completed the questionnaires with a response rate $88.2 \%$. While patients' sample was calculated using MedCalc software version 16.1 (৫1993-2016 MedCalc Software). Depending on [7].

The least calculated sample size was 257 which increased to 300 patients allowing for more accuracy.

Tool of data collection :A pre-designed and coded questionnaires in English language were filled by the physicians to assess their knowledge about PRs .It included socio-demographic and work-related data, in addition to 20 questions adopted and modified from the Egyptian Hospital Accreditation Standards (Foundation level) 2014,[11]. The total possible scores ranged from $0(0.0 \%)$ to $20(100 \%) \&$ score equal to or higher than $12(60 \%)$ was considered satisfactory,[12,13]. Similar questionnaire in Arabic language was distributed on patients to assess the physicians' practice of PRs from patient's perspectives. It included Socio-demographic \& department of admission and LOS in addition to the previously mentioned 20 questions. The same rules for score calculation were followed.

Ethical consideration: A written informed consent was obtained from the patients and their guardians as well as physicians. it included data about aim of the work, study design, site, time, subject and tool. They were informed that all collected data will be confidential and used for scientific purposes only. Also, an administrative approval from The Research Ethics Committee of Faculty of Medicine Benha University 
and an official permission from the dean of the faculty as well as Benha University Hospitals administrators was obtained.

Data management: All statistical analyses were carried out using (SPSS, version 20). Quantitative data were tested for normality using Kolmogorov-Smirnov test. Qualitative data were demonstrated in terms of frequency and percentage and quantitative data were summarized as mean \pm SD. Statistical comparisons between the different study groups were carried out using Chi-square test or Fishers Exact test. A p-value $<0.05$ was considered statistically significant, and a $p$-value $<0.01$ was considered highly significant.

\section{Results}

The most common age group was 30 to less than 40 years old, slightly more than two thirds of the studied group were males, almost two third of the physicians had M.D degree, around $27.8 \%$ of the physicians were professors, $27.3 \%$ of them were from $0 \& G$, slightly less than half of the studied group had work experience less than 10 years, and nearly two thirds of the studied group works less than 8 hours per day. (see Fig. 1)

There was statistically significant difference between physicians' score of knowledge about PRs regarding their age, gender, highest qualification, and work position, work experience and average number of working hours, while no statistically significant difference considering department of work. (see Table 1)

The most common age group among studied patients was 30 to less than 45 years old. The table also shows that more than two thirds of the studied patients were females, $36.3 \%$ of them were not educated, and $73.3 \%$ of the participants were not working. The table also shows that most of the studied patients were rural residents. The table also illustrates that equal number of patients were participated in the selected departments. It also shows that almost two thirds of them were admitted in the hospital for less than one week. (see Fig. 2)

There was statistically significant difference between physicians' score of practices of PRs from patients' point of view considering patients' gender, educational level and department of admission, while there were no statistically significant difference regarding residence and LOS of patients. (see Table 2)

There was statistically significant difference between knowledge and practices scores of PRs. (see Table 3)

\section{Discussion}

Our study revealed that the score of knowledge about PRs was affected by physicians' age, gender, highest qualification, work position, work experience and average number of working hours. These findings disagreed with [1] who stated that physicians' awareness regarding patients' rights did not differ 
significantly between physicians of different age groups and gender. This difference can be explained that the more the age of the physician, the more to have post graduate studies and the more to have chance to get more knowledge about PRs. Also, the physician after M.D degree start to practice medicine in his/her private clinics and start to depend on him/herself when dealing with the patient without any assistance and this can stimulate them to increase their knowledge about both medical and ethical aspects while dealing with the patients.

Regarding physicians' highest qualification and work position, our finding came consistent with [1] who stated that the awareness score of the physicians differed significantly according to their qualification with higher mean scores for those who obtained postgraduate studies in comparison with physicians with $\mathrm{MBBCH}$ degree only. This can be explained that healthcare staff with higher qualification has higher work position and more work experience.

Regarding physicians' work experience, our finding came consistent with [14] who stated that the physicians' experience in medical practice is associated with higher awareness regarding patients' rights.

Patients' opinion in physicians' practice of PRs was affected by his/her gender, educational level and department of admission, but not affected by patients' residence or LOS.

In term of patients' gender and educational level, our findings were inconsistent with [4] who showed that there were no statistically significant relation between patients' perspectives about PRs and his/her gender and educational level.

Also, our findings came against [15] who found that there was no statistically significant relation between practicing PRs and patient sex, educational level, place of residence.

As regarding gender, in our study male patients showed higher score of satisfaction about physicians practice of PRs than that of females, this can be explained that females usually seeks higher and better level of service.

As regarding educational level, our study showed that the higher the educational level of the patients, the more prone to higher level of adequate practicing of PRs. In general, more educated persons are more aware of their rights and as a result of that they will seek higher quality level of service.

In term of patients' residence or LOS, our findings were in accordance [4] who showed that there was insignificant relation between patients' perspectives about PRs and residence and hospital stay

In contrast, [15] revealed that there was statistically significant relation between practicing PRs (patient satisfaction) and duration of hospitalization.

It has been found that there was low level of practicing PRs ( $14.7 \%$ only shows an adequate score equal to or higher than $60 \%$ ). These results agreed with,[9]. His study demonstrated that only $5.0 \%$ of physicians and nurses had good practice in Alexandria General University Hospital (AGUH) and $0.0 \%$ in 
Matrouh General Hospital (MGH), $42 \%$ had moderate practice in AGUH versus $29 \%$ of physicians and nurses in $\mathrm{MGH}$, and finally, $53 \%$ of physicians and nurses of the AGUH versus $71 \%$ in $\mathrm{MGH}$ had poor practice. [16] claimed that insufficient staffing, low salaries, negligence of the nurses' rights, burn-out, long working hours, lack of performance standards in hospitals, and lack of enough equipment are the factors leading to poor observance of the patients' rights. [17] found that hospital policy, equipment and supplies, health work environment, employer guideline and job description importantly affect practicing patients right. [18] discussed causes of low level of practice of PRs and found that it can be attributed mainly to lack of knowledge about PRs among patients and health care providers. Also, personnel dissatisfaction, insufficient number of health staff, and lack of necessary facilities in PHC centers are among the important obstacles in proper practicing of PRs.

\section{Conclusion}

There was discrepancy between knowledge and practices of PRs. As regard knowledge, almost all physicians $(97.0 \%)$ had satisfactory score of knowledge. As regard practice, the majority of physician $(85.3 \%)$ had inadequate score and only $(14.7 \%)$ of the physicians who have adequate score.

\section{Declarations}

-Ethics approval and consent to participate: We obtained ethical approval from Research Ethics Committee of Faculty of Medicine Benha University on 7-11-2018

-Consent for publication: Not applicable.

- Availability of data and materials: The datasets used and/or analysed during the current study are available from the corresponding author on reasonable request.

-Competing interests: The authors declare that they have no competing interests.

-Funding The authors have not declared a specific grant for this research from any funding agency in the public, commercial or not-for-profit sectors.

- Authors' contributions: Abdel-Rahim Shoulah choosed the topic of the paper and contributed in construction of the tool. Rabaa Abed Al-Hady, Rasha EL-Desouky, Eman Araby and Enjy Khedr made substantial contribution to the manuscript and revised it critically. All authors have read and approved the final manuscript.

- Acknowledgements: We would like to thank the staff member of the four departments as well as patients admitted to these departments for their invaluable help in this study.

\section{References}


1. I. Abu Saq, N. Al-Hutaylah, M. AL-Shahrani, et al., "Assessment of Primary Health Care Physicians' Awareness about Patients' Rights". The Medical journal of Cairo University. vol. 85, no. 2, pp. 651655, 2017.

2. S. Rosenbaum, "Managed Care and Patients' Rights". Journal of the American Medical Association., vol. 289, no. 7, pp. 906-907, 2003.

3. A. Fernandes, S. D'Cunha and S.Suresh, "Patient Rights: Awareness and Practice in a Tertiary Care Indian Hospital". International Journal of Research Foundation of Hospital \& Healthcare Administration. vol. 2, no. 1, pp. 25-30, 2014.

4. S. Mohammed, A. Shabla and S., Wehieda, "Patients' Rights: Patients' and Nurses' Perspectives". IOSR Journal of Nursing and Health Science. vol. 4, no. 4, pp. 54-60, 2015.

5. A. Parsapoor, A. Bagheri and B. Larijani, "Patient's Rights Charter in Iran". Acta Medica Iranica. vol. 52, no. 1, pp.24-28, 2012.

6. Z. Mastaneh and L.Mouseli, "Patients' Awareness of Their Rights: Insight from a Developing Country". International Journal of Health Policy and Management. vol. 1, no. 2, pp. 143-144, 2013.

7. R. Eldesouky, M. El Bakry, H. El Ghaiaty et al., "Patients' Rights: Awareness of the Pediatric Patients' Guardians Attending Benha University Hospital". The Egyptian Journal of Community Medicine. vol. 33, no. 2, pp.15-30, 2015.

8. S. El-Sobkey, A.M. Almoajel and M.N.Al-Muammar, "Knowledge and attitude of Saudi health professions' students regarding patient's bill of rights". Int J Health Policy Manag. vol. 3, no. 3, pp. 117-122, 2014.

9. M. Ghanem, H. Megahed, N.A. Aly, "Practice of Patient's Rights Among Physicians And Nurses In Two Egyptian Hospitals From Patients 'Perspective". Journal of Natural Sciences Research. vol. 5, no. 16, pp. 159-169, 2015.

10. United State Agency International Development. Egyptian Hospital Accreditation Program Standards. 6th ed. Bethesda, MD: The Partners for Health Reform plus Project, Abt Associates Inc. Available at URL: www.PHRplus.org. 2005.

11. Accreditation Executive Committee. Egyptian Healthcare Accreditation Program. Standard for Hospital (Foundation Level). 2014

12. F. Hafez, H. Mohamed and D.EltabeySobeh, "Assessment of Nurses' Knowledge and Practice Regarding Professional Ethics in Outpatient Clinics at Mansoura University Hospital". IOSR Journal of Nursing and Health Science. vol. 5, no. 6, pp. 20-28., 2016.

13. M. Hassan, E. El-Karmalawy and M. Hassan, "Assessment of professional ethics practiced by nurses working in primary health care centers in portsaid". Journal of American Science. vol. 8, no. 12, 2012.

14. A. Parsapoor, K. Mohammad, H.M. Afzali, et al., "Unsatisfied patient's rights: A survey on the views of patients, nurses and physicians". Journal of Medical Ethics and History of Medicine. vol. 5, pp.19, 2012.

15. Z. Anbari, M. Mohammadi, M.Taheri, "Satisfying patients' rights in Iran: Providing effective strategies". Iranian journal of nursing and midwifery research. vol. 20, no. 2, pp.184-189, 2015. 
16. A. Sheikhtaheri, M. Jabali and Z. Dehaghi, "Nurses' knowledge and performance of the patients' bill of rights". Nursing ethics. vol. 23, no.8, pp. 866-876, 2016.

17. K. Elsayed, O. El-Melegy and A. El-Zeftawy, "The Effect of an Educational Intervention on Nurses' Awareness about Patients' Rights in Tanta". Journal of American Science. vol. 9, no. 9, pp. 210-219, 2013.

18. S.Alghanim, "Assessing knowledge of the patient bill of rights in central Saudi Arabia: a survey of primary health care providers and recipients". Annals of Saudi medicine. vol. 32, no. 2, pp. 151-155, 2012.

\section{Tables}

Table (1): Factors affecting physicians' score of knowledge about PRs 


\begin{tabular}{|c|c|c|c|c|}
\hline \multirow{2}{*}{$\begin{array}{l}\text { Score } \\
\text { Factors }\end{array}$} & \multirow{2}{*}{$\begin{array}{l}\text { Satisfactory } \\
\text { No (\%) }\end{array}$} & \multirow{2}{*}{$\begin{array}{l}\text { Unsatisfactory } \\
\text { No (\%) }\end{array}$} & \multirow[t]{2}{*}{ FET } & \multirow[t]{2}{*}{$\mathrm{p}$ Value } \\
\hline & & & & \\
\hline \multicolumn{5}{|l|}{ Age } \\
\hline$<30$ & $30(88.2)$ & $4(11.8)$ & & $0.013^{*}$ \\
\hline $30-$ & $91(97.8)$ & $2(2.2)$ & \multirow[t]{3}{*}{8.5} & \\
\hline $40-$ & $31(96.9)$ & $1(3.1)$ & & \\
\hline 50 and more & $71(100.0)$ & $0(0)$ & & \\
\hline \multicolumn{5}{|l|}{ Gender } \\
\hline Male & $153(98.7)$ & $2(1.3)$ & \multirow[t]{2}{*}{4.9} & \multirow[t]{2}{*}{$0.026 *$} \\
\hline Female & 70 (93.3) & $5(6.7)$ & & \\
\hline \multicolumn{5}{|l|}{ Highest Qualification } \\
\hline $\mathrm{MBBCH}$ & $19(86.4)$ & $3(13.6)$ & & \\
\hline Master & $52(96.3)$ & $2(3.7)$ & \multirow[t]{2}{*}{7.6} & \multirow[t]{2}{*}{$0.012^{\star}$} \\
\hline M.D & $152(98.7)$ & $2(1.3)$ & & \\
\hline \multicolumn{5}{|l|}{ Work Position } \\
\hline Resident & $19(86.4)$ & $3(13.6)$ & & \\
\hline Assistant Lecturer & $52(96.3)$ & $2(3.7)$ & \multirow[t]{4}{*}{7.9} & \multirow[t]{4}{*}{$0.031 *$} \\
\hline Lecturer & $52(98.1)$ & $1(1.9)$ & & \\
\hline Assistant Professor & $36(97.3)$ & $1(2.7)$ & & \\
\hline Professor & $64(100.0)$ & $0(0.0)$ & & \\
\hline \multicolumn{5}{|l|}{ Department } \\
\hline Internal Medicine & $50(92.6)$ & $4(7.4)$ & \multirow[t]{4}{*}{4.5} & \multirow[t]{4}{*}{0.14} \\
\hline General Surgery & $51(100.0)$ & $0(0.0)$ & & \\
\hline Pediatrics & $60(96.8)$ & $2(3.2)$ & & \\
\hline O\&G & $62(98.4)$ & $1(1.6)$ & & \\
\hline \multicolumn{5}{|l|}{ Work Experience } \\
\hline$<10$ & $92(93.9)$ & $6(6.1)$ & \multirow[t]{3}{*}{5.7} & \multirow[t]{3}{*}{$0.036 *$} \\
\hline $10-$ & $44(97.8)$ & $1(2.2)$ & & \\
\hline 20 and more & $87(100.0)$ & $0(0.0)$ & & \\
\hline
\end{tabular}




\begin{tabular}{|lllll|}
\hline $\mathbf{8}$ hours & $150(99.3)$ & $1(0.7)$ & 8.4 & $0.004^{\star *}$ \\
$>$ than 8 & $73(92.4)$ & $6(7.6)$ & & \\
\hline
\end{tabular}

FET.....Fisher's Exact Test

*significant

**highly significant

Table (2): Factors affecting physicians' score of practice of PRs 


\begin{tabular}{|c|c|c|c|c|}
\hline Score & Adequate & Inadequate & Chi Square Test & $p$-Value \\
\hline Factors & No (\%) & No (\%) & & \\
\hline \multicolumn{5}{|l|}{ Gender } \\
\hline Male & $27(27.6)$ & $71(72.4)$ & 19.3 & $<0.001$ ** \\
\hline Female & $17(8.4)$ & $185(91.6)$ & & \\
\hline \multicolumn{5}{|l|}{ Educational Level } \\
\hline Non-Educated & $12(11.0)$ & $97(89.0)$ & & \\
\hline Read and Write & $15(20.5)$ & $58(79.5)$ & 14.54 & $0.006 * \star$ \\
\hline Basic Education & $6(15.4)$ & $33(84.6)$ & & \\
\hline Secondary Education & $9(9.5)$ & $86(90.5)$ & & \\
\hline University Education & $8(34.8)$ & $15(65.2)$ & & \\
\hline Residence & & & 0.3 & 0.600 \\
\hline Rural & $35(14.2)$ & $212(85.8)$ & & \\
\hline Urban & $9(17.0)$ & $44(83.0)$ & & \\
\hline \multicolumn{5}{|c|}{ Department of Admission } \\
\hline Internal Medicine & & & 16.8 & 0.001 ** \\
\hline General Surgery & $19(25.3)$ & $56(74.7)$ & & \\
\hline Pediatrics & $9(12.0)$ & 66 (88.0) & & \\
\hline \multirow[t]{2}{*}{$O \& G$} & $14(18.7)$ & $61(81.3)$ & & \\
\hline & $2(2.7)$ & $73(97.3)$ & & \\
\hline \multicolumn{5}{|l|}{ LOS } \\
\hline$<1$ week & $30(15.1)$ & $169(84.9)$ & 2.8 & 0.247 \\
\hline 1-2 weeks & $7(10.0)$ & $63(90.0)$ & & \\
\hline$>2$ weeks & $7(22.6)$ & $24(77.4)$ & & \\
\hline
\end{tabular}

Table (3): Comparison between knowledge and practices score

\begin{tabular}{|lllrl|}
\hline Score & $\begin{array}{l}\text { Knowledge Score } \\
(\mathrm{N}=230)\end{array}$ & $\begin{array}{l}\text { Practices Score } \\
(\mathrm{N}=300)\end{array}$ & z- test & p value \\
\hline Score $\geq 60 \%$ & $223(97.0)$ & $44(14.7)$ & 18.8 & $<0.001$ ** \\
\hline Score $<60 \%$ & $7(3.0)$ & $256(85.3)$ & 18.8 & $<0.001$ ** \\
\hline
\end{tabular}


Figures

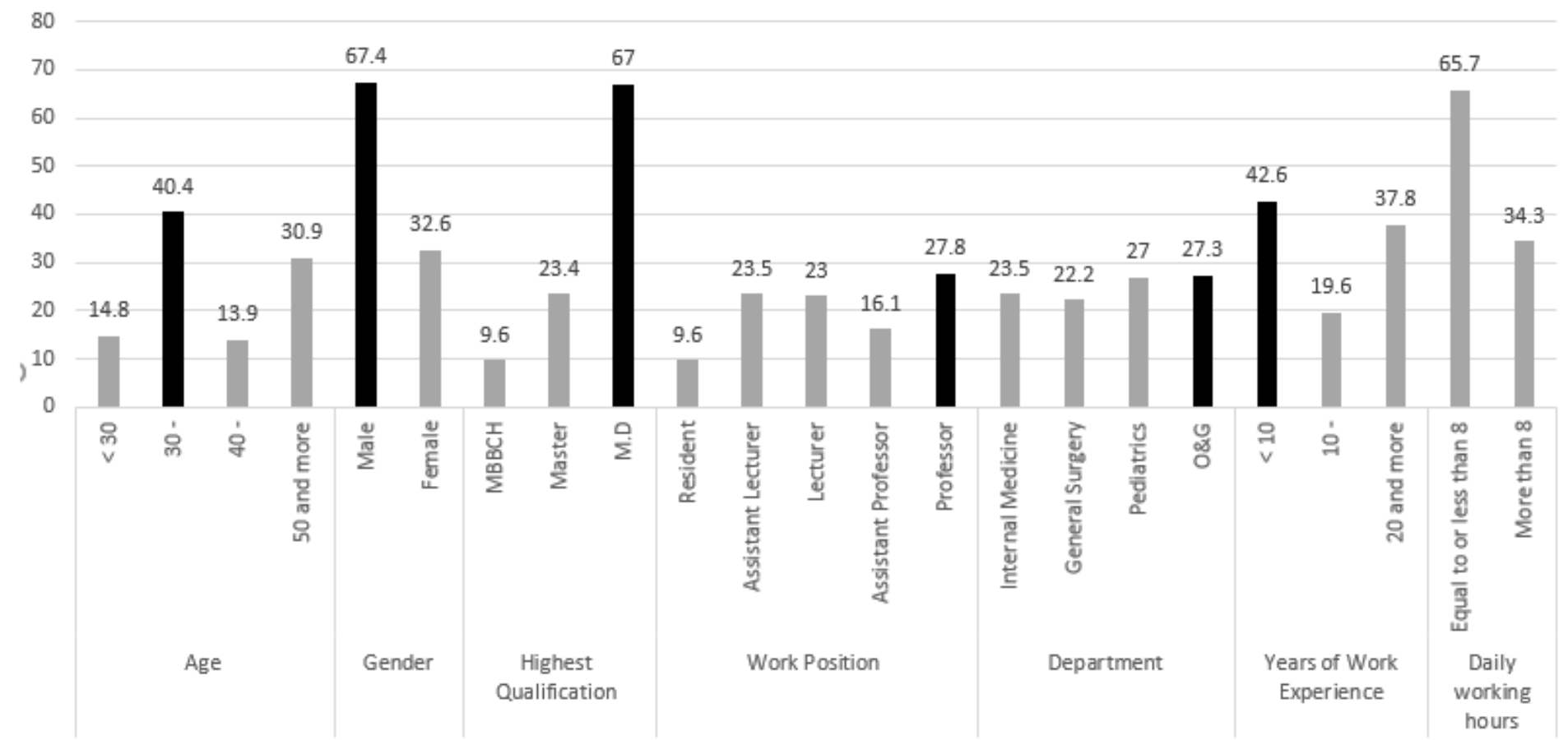

Figure 1

Socio-demographic and work-related characteristics of physicians

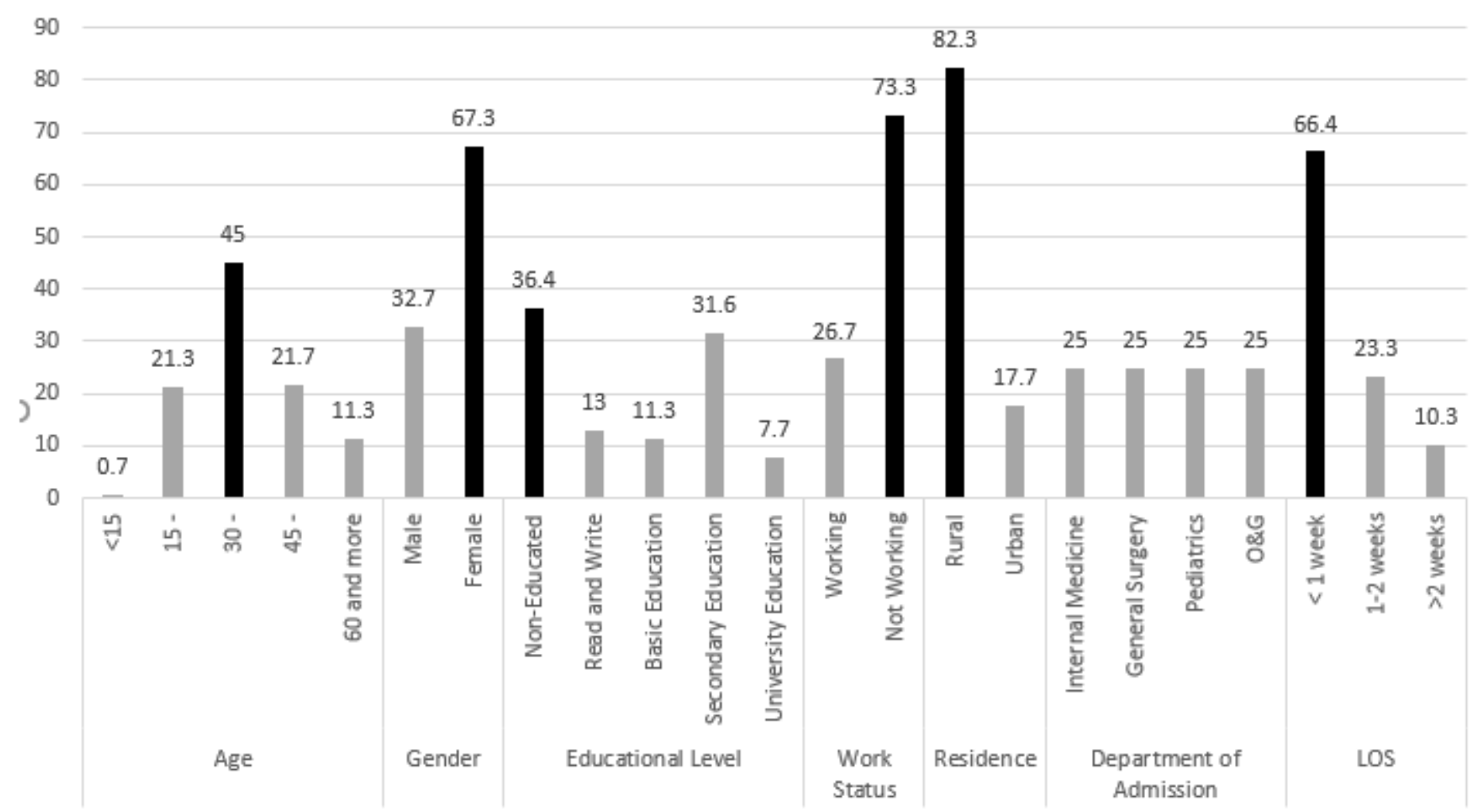


Figure 2

Socio-demographic and hospital-related characteristics of patients 